\title{
A simple equation to determine the breakdown of individual aggregate size fractions in the wet-sieving method
}

\begin{abstract}
Wet-sieving method using nested sieves is one common method to measure aggregate stability. However, this method cannot be used to measure the stability of individual aggregate size fractions, only of whole soils. Thus, this study was to develop an equation to estimate the aggregate breakdown of individual aggregate size fractions in this particular method. The key to develop the equation was to assume that aggregate breakdown happens sequentially and consistently, and that the aggregate breakdown between any two aggregates in the same aggregate size fractions is equal in percentage. Applying these two assumptions, this equation was developed: $\mathrm{xi}=($ Wai $\times \mathrm{Di}) /($ Wai+Dii 1$)$, where $\mathrm{xi}$ is the weight of aggregate breakdown in aggregate size fraction $i$, Wai is the weight of the aggregates in aggregate size fraction i before wet-sieving, and Di and Diī 1 are the weight of aggregates that have passed through sieve $\mathrm{i}$ and $\mathrm{i}$ 1, respectively. This equation was tested with five soil series. The soils were separated into six aggregate size fractions: 4.76ї 8.0, 2.83ї 4.76, 2.0ї 2.83, 1.0ї 2.0, $0.5 \mathrm{i}$ 1.0 and $0.3 i ̈ 0.5 \mathrm{~mm}$. For every soil, each of their aggregate size fraction was separately wetsieved to determine the actual aggregate breakdown. The separate wet-sievings results were then combined in such a way to simulate the usual wet-sieving method; that is, to construct the data that would have been produced if each of the aggregate size fractions was wet-sieved together in the same nested sieves. Paired sample t-test showed that the differences between the actual and estimated aggregate breakdown values were significant at 5\%. However, there was very close correlation between the actual and estimated values $(r=0.974 ; p<0.001)$; thus, the equation was calibrated by simple linear regression. The calibrated equation was: $\hat{R}=100$ $\sin 2 \breve{U}$, where $\hat{R}$ is the calibrated breakdown estimate for aggregate size fraction i, and $\breve{U}$ is $0.0166 \mathrm{xi}+0.1$ in unit radians. This calibrated equation was highly significant at $1 \%$ $(\mathrm{F}=766.039 ; \mathrm{p}<0.001)$, with the values fitting very tightly along the regression line $(\mathrm{R} 2=0.961)$, and with very small standard error (std. error $=0.023$ ). The calibrated equation was validated with three additional soils. Paired sample t-test showed there was insignificant differences between the actual and calibrated breakdown estimate values. Moreover, using fewer aggregate size fractions did not affect the accuracy of the calibrated equation, as this equation still predicted the actual values with very small errors.
\end{abstract}

Keyword: Aggregate breakdown; Wet-sieving; Nested sieves; Aggregate stability 